\title{
As relações de classe e gênero no contexto de práticas orientadas pela mídia: apontamentos teóricos
} Ana Carolina Damboriarena Escosteguy e Lírian Sifuentes

\section{Resumo}

0 objetivo aqui é apresentar uma discussão teórica sobre dois eixos centrais do projeto $A$ visibilidade da vida ordinária de mulheres destituídas na mídia: a) o entrecruzamento das categorias posição de classe e gênero e b) a singularidade dos estudos sobre identidade em relação aos estudos de recepção e de consumo midiático. 0 destaque dessas questões deve-se à sua diversidade de entendimentos em circulação e, consequentemente, o esclarecimento dos posicionamentos assumidos. Em relação ao primeiro eixo, pretende-se que a articulação entre classe e gênero colabore na percepção do peso relativo de cada um desses termos. Em relação ao segundo, parte-se do pressuposto que são três linhagens diferentes - estudos de recepção, de consumo e de identidade - que têm objetos distintos, portanto, conservam uma diferenciação entre si, embora as estratégias metodológicas possam ser convergentes. Por fim, afirma-se que a pesquisa almeja estar situada no campo dos estudos de práticas orientadas pela mídia, na tentativa de descentrar a análise tanto das representações, quanto das relações discretas entre os atores e a mídia, implicadas nos estudos de recepção, bem como nos de consumo midiático.

\section{Palavras-chave:}

Classe social. Relações de gênero. Mulheres destituídas. Práticas orientadas pela mídia.

Ana Carolina Damboriarena Escosteguy I carolad@pucrs.br Doutora em Ciências da Comunicação pela Universidade de São Paulo (USP). Professora da Pontifícia Universidade Católica do Rio Grande do Sul (PUC-RS).

Lírian Sifuentes | lisifuentes@yahoo.com.br

Doutoranda (PUC-RS); Professora do curso de Jornalismo da Universidade Comunitária da Região de Chapecó (Unochapecó).

\section{Considerações iniciais}

0 projeto de pesquisa $A$ visibilidade da vida ordinária de mulheres destituídas na mídia tem por objetivo investigar a visibilidade que mulheres de posições sociais destituídas adquiriram na mídia, mediante a circulação de histórias pessoais, depoimentos, testemunhos e diários. Duas questões demarcam seu escopo. A primeira delas diz respeito às próprias narrativas pessoais, observando quais os valores e representações que estão aí articulados. ${ }^{1}$ A segunda trata da existência de transformações que tais narrativas midiatizadas produzem no mundo social, entendendo que a mídia acarreta consequências para outras práticas e espaços sociais. Nesse contexto, apresentamos apontamentos teóricos sobre 0 cruzamento entre as relações de classe e gênero e, posteriormente, sobre as especificidades dos estudos de identidade em relação aos estudos de recepção e de consumo midiático. 0 destaque dessas questões deve-se à diversidade de entendimentos em circulação sobre as mesmas $\mathrm{e}$, consequentemente, 0 esclarecimento dos posicionamentos assumidos na pesquisa citada. 
Uma determinada concepção de classe e gênero atravessa nossa proposta de pesquisa, fundamentando tanto a primeira quanto a segunda questão. Esse balizamento teórico constitui os dois primeiros vetores do artigo. Já no terceiro vetor pretende-se uma discussão sobre os estudos de recepção e consumo, bem como sobre os estudos de identidade, esses especificamente referidos ao campo dos estudos de mídia, tendo como objetivo embasar as opções de desenvolvimento da pesquisa que está implicada na segunda questão norteadora da investigação em tela.

\section{Posições de classe: pensando os destituídos}

Em primeiro lugar, pretende-se seguir a orientação de Santos (2009, p. 465), quando afirma que "classe social deve ser considerada uma noção relacional". Trata-se, portanto, de localizar as posições destituídas dentro de um conjunto social mais abrangente, levando sempre em consideração a estrutura social brasileira como um todo, mesmo que de maneira bastante simplificada.

De modo genérico, partimos do princípio de que 0 Brasil vivenciou na última década um processo em que novos segmentos da sociedade brasileira foram incorporados ao mercado de consumo, o que aconteceu, sobretudo, em razão do aumento do poder aquisitivo, dos programas governamentais de distribuição de renda, do incremento a serviços e mecanismos financeiros e do crescimento da oferta de crédito aos indivíduos de baixa renda. Apesar de todo o otimismo dos dados econômicos, revelados pela renda e padrão de consumo, permitindo classificar aproximadamente 94,4 milhões de brasileiros como pertencentes à classe média (IPEA, 2009), as histórias familiares, as vivências na infância (pobreza, trabalho infantil, gravidez e casamento precoces etc.), o conjunto de predisposições que configuram 0 comportamento prático dos indivíduos, a visão de mundo transmitida pelos pais - ou por aqueles que os substituem - aos filhos evidenciam sua origem e seu pertencimento a uma determinada classe social. ${ }^{2} \mathrm{Ou}$ seja, mesmo que muitos desses brasileiros tenham tido experiências de diferentes graus de sucesso econômico, continuam até hoje vivenciando uma realidade social e cultural que, em termos de aprendizado, valores, experiências próprias, hábitos de lazer, visão de mundo e, principalmente, ocupação profissional (fundamentalmente, trabalho manual), pode ser definida como dentro do âmbito das posições sociais destituídas.

0 desenvolvimento dessa questão se concentra na concepção de "narrativas pessoais midiatizadas" e na identificação de padrões e lógicas comuns à diversidade de relatos aí enquadrados, tema explorado e apresentado Escosteguy (2011), na palestra The Media Visibility of Disadvantaged Social Classes within Brazilian Mediascape, na Westminster University.

Essa questão foi investigada na pesquisa coordenada por Lúcia Helena Alves Müller, $A$ dimensão simbólica dos processos de inclusão financeira e oferta de crédito a grupos populares, que contou com o financiamento da PUCRS (2009/2010) e com a colaboração de Ana Carolina Escosteguy. 
Entendemos, seguindo, sobretudo, as pesquisas e reflexões de Jessé Souza (2006, 2009), que, para além de uma posição de classe referente estritamente a uma desigualdade econômica, 0 termo "classe" é relativamente um sistema dinâmico que é continuamente feito e refeito, tanto em larga escala, pela lógica do capital, quanto através de valores e representações que constituem a vida afetiva e emocional. Sendo assim, busca-se um olhar que ultrapasse discussões mais tradicionais de classe que se restringem ao espaço da renda. Como já foi dito antes, pode-se observar casos diferenciados de ascensão econômica, sem que isso signifique uma ruptura com valores e modos de ser próprios da posição de classe de origem.

Interessa, aqui, destacar que a divisão social gera consequências na vida dos indivíduos e que, por essa razão, os indivíduos têm distintas capacidades para a ação e, portanto, chances de vida. ${ }^{3}$ Tratase de combinar, na definição de classe social, tanto a esfera material associada às instituições econômicas, quanto à esfera cultural, que diz respeito às práticas sociais e culturais, isto é, como os indivíduos e grupos sociais pensam ou procedem em relação ao casamento, ao trabalho, à religião, à educação etc. ${ }^{4}$

Por classes destituídas compreendemos, então, aquelas compostas por indivíduos que não têm domínio sobre os recursos produtores de valor e que ocupam posições desprivilegiadas no mercado de trabalho ou até mesmo podem estar excluídos desse. A operacionalização dessa conceituação, em Santos (2009), está focalizada na divisão social do trabalho. Através dela, localizam-se distintas posições destituídas dentro da estrutura social. Em síntese, as correspondentes categorias empíricas são: trabalhador braçal (trabalhador manual agrícola, trabalhador na manutenção de edifícios e logradouros, trabalhador na pecuária, ajudante de obras civis, trabalhador na agropecuária em geral, trabalhador de cargas e descargas, trabalhador de serviços diversos), empregado doméstico (usa habilidades básicas de cuidado do lar), trabalhador que não dispõe de local fixo para o trabalho (pedreiro, vendedor ambulante, mestre de construção civil, pintores, trabalhador em serviços de higiene e embelezamento, operador de máquina de costura), pequenos lavradores (pequenos produtores que têm muito pouca terra), incluindo os desempregados. Traduzem-se, assim, em ocupações que não necessitam de qualificação formal e, por consequência, não possuem reconhecimento social.

Embora "ser destituído" tenha relação com questões de renda, uma vez que as ocupações 
citadas são geralmente mal remuneradas e, com frequência, a ausência de qualificação profissional se origina da falta de possibilidades financeiras para acessar uma educação mais especializada, pensa-se a posição de classe social não restrita ao fator econômico. Em outros termos, trata-se de pensar a articulação entre os "capitais econômico e cultural", sendo esse último uma combinação da herança dos valores familiares e do capital escolar, como "elementos estruturais" da "hierarquia social" de toda sociedade moderna (SOUZA, 2009).

\section{As relações de gênero: pensando as identidades femininas}

0 conceito de gênero remete de modo forte, de um lado, às noções de relação, diferença e multiplicidade, de outro, procura desestabilizar o determinismo biológico, uma noção de universalidade e de essência. Com esse objetivo, a discussão busca introduzir elementos culturais e sociais no debate sobre as desigualdades entre masculinidades e feminilidades. Contudo, não se pretende revisar a trajetória do conceito nem enumerar suas inúmeras e variadas possibilidades interpretativas. Assumimos que seu entendimento diz respeito a um construto social, implicando na existência de valores, regras, posturas, obrigações e deveres que expressam o que é ser homem ou ser mulher numa dada cultura ou sociedade.

Talvez seja necessário enfatizar que o gênero não fica subsumido na classe, "ao contrário, a consciência da diferença dessas formas de solidariedade deve ajudar a percepção do peso relativo de cada qual" (MATTOS, 2006, p. 164). Se, por um lado, sabe-se que o marxismo não deu destaque às questões propriamente femininas, por outro, os estudos feministas, inicialmente realizados por mulheres majoritariamente brancas de classe média, deixaram de abordar aspectos relacionados às mulheres negras e de classes populares, por exemplo. Stolke (2004) fala de uma miopia de raça e classe entre as estudiosas feministas. Trabalhos sobre etnia e classe social ganharam destaque apenas nas últimas duas décadas, com o objetivo de dar voz às mulheres que não se encaixavam nos modelos que costumavam representar os estudos de gênero: mulheres brancas, ocidentais e de classe média. Essa convergência entre posições de classe e gênero reflete um comprometimento com uma reflexão sobre a história, repleta de diferentes formas de opressão (SCOTT, 1986). De tal modo, consideramos mais pertinente endossar 0 entendimento de que os vínculos de dominação são "relacionais", sejam eles entre classes sociais, bem como entre homens e mulheres (MATTOS, 2006).

Tal como se percebe entre as classes sociais, nas relações de gênero haveria igualmente uma "classe" desmerecida. Se o masculino representaria a cultura, o superior, a mente, o raciocínio; 0 feminino estaria relacionado à natureza, ao inferior, ao corpo, à emoção (BOURDIEU, 2007). Considerando que a cultura se organiza em torno de sistemas classificatórios em que se identificam ao menos dois grupos opostos - nós e eles -, essa oposição traz à tona 0 
desmerecimento de uma das partes, visto que não há um equilíbrio de poder entre os elementos em contraste (WOODWARD, 2000). Nas relações de gênero, a mulher é o lado "fraco" dessa oposição.

Scott (1986) vale-se do pensamento de Pierre Bourdieu - que examina as relações de gênero como espaço primário em que o poder é articulado - para defender que as diferenças biológicas e a divisão de trabalho na procriação e reprodução operam como a melhor das ilusões coletivas. Baseadas em referências "objetivas", as diferenças de gênero estruturam as percepções sociais. "Na medida em que essas referências estabelecem distribuições de poder, o sexo torna-se implicado na concepção e construção do próprio poder" (SCOTT, 1986, p. 1069). Dito de outra forma, as diferenças sexuais/físicas legitimam a dominação masculina. A autora propõe, então, uma definição de gênero em que destaca dois aspectos centrais: "gênero é um elemento constitutivo de relações sociais baseadas em diferenças percebidas entre os sexos, e gênero é uma forma primária de significar relações de poder" (SCOTT, 1986, p. 1067).

Refletindo sobre a conformação das identidades de gênero, Scott ressalta ainda como sua característica a instabilidade. Porém, uma ilusória separação nítida entre homens e mulheres é evidenciada em nossa sociedade, criando a falsa imagem de identidades femininas e masculinas fixas.

A identificação, embora pareça sempre fixa e coerente, é, na verdade, bastante instável.
Como as próprias palavras, as identidades subjetivas são processos de diferenciação e distinção, exigindo a supressão de ambigüidades e elementos opostos para assegurar (e criar a ilusão de) coerência e entendimento comum. [...] Além disso, as idéias de masculino e feminino não são fixas, pois variam de acordo com o contexto de uso. [...] Esse tipo de interpretação faz das categorias 'homem' e 'mulher' problemáticas, sugerindo que masculino e feminino não são características inerentes, mas subjetivamente (ou ficcionalmente) construídas. Essa interpretação também significa que 0 subjetivo está em um constante processo de construção (SCOTT, 1986, p. 1063-1064).

Consequentemente, nosso foco concentra-se numa vertente não-essencialista, que enfatiza a construção social das identidades, contrária a concepções que as compreendem como uma categoria inerente e inata a grupos e/ou comunidades. Entende-se que as identidades estão em permanente construção, metamorfoseandose constantemente, atravessadas tanto pelos discursos públicos quanto pelas práticas e experiências dos sujeitos, entranhados numa determinada conjuntura histórica.

Para Bourdieu (2007), a identidade de uma mulher é constituída desde muito cedo, de modo que possa aprender a agir e pensar como uma mulher. A aprendizagem ganha eficiência por ser tácita e incessante. Além disso, por serem as identidades, feminina e masculina, definidas como antagônicas, aquilo que para os homens é incentivado, para as mulheres é continuamente reprimido: uma moça deve sentar de pernas fechadas, não pode expor determinadas partes 
do corpo, deve ser delicada, vaidosa e servir às outras pessoas.

De forma convergente, a maneira como os papéis de cada gênero se estrutura é tão forte que se torna "natural". Isso fica claro quando se fala em mulheres e maternidade. Ao envolveremse de forma destacada na geração dos filhos, especialmente por carregá-los por nove meses no ventre e ainda amamentá-los, as mulheres possuem, historicamente, uma menor mobilidade, pois necessitam ficar mais tempo envolvidas no cumprimento dessas tarefas. Essa demanda acarretou uma associação "natural" entre a maternidade e as tarefas de casa. Assim, 0 envolvimento das mulheres com as crianças na primeira infância é compreensível, todavia "daí a considerar o trabalho doméstico como o trabalho 'natural' das mulheres, há muito caminho. Não é por ter a capacidade de ter filhos que as mulheres nascem sabendo passar e costurar" (LAMAS apud MATA, 1996, p. 69).

Ainda, seguindo as reflexões de Franchetto, Cavalcanti e Heilborn (1981, p. 43), a questão "o que é ser mulher?" carece de respostas definitivas, uma vez que esse significado não é dado universalmente, e sim por meio de contextos concretos, particulares a cada cultura. Do ponto de vista de Franchetto, Cavalcanti e Heilborn (1981, p. 32-33), implica na "percepção de que não existe a Mulher, e sim mulheres".

A mulher, como sujeito social que se afirma, não é uma realidade homogênea e monolítica, mas vive, existe na concretude das diferenças sociais e culturais que a constituem. A profunda compreensão da afirmação de Beauvoir (1980) de que 'não se nasce mulher, torna-se mulher'.

Por fim, cabe destacar que a articulação entre os dois aportes teóricos, recém explicitados, a respeito das posições de classe e gênero, contribui para tomar como mulher destituída aquela identificada como trabalhadora braçal, independente da renda obtida, por ser essa uma atividade pouco valorizada na sociedade, da mesma forma que não exige habilidades e conhecimentos formais que dependam de formação específica. Sendo assim, a pesquisa empírica que será desenvolvida futuramente com o objetivo de identificar as consequências da visibilidade midiática dos destituídos sobre os modos de vida de determinado grupo social estará concentrada em histórias de domésticas, manicures, depiladoras, costureiras, trabalhadoras em serviços de limpeza, vendedoras ambulantes.

\section{Um lugar de onde investigar as posições de classe e de gênero}

Esta última seção pretende problematizar 0 desenvolvimento dos estudos de recepção, consumo e identidades, a partir de um olhar situado na comunicação, tendo como horizonte a necessidade de identificar um campo de estudo que dê suporte para viabilizar nossa pesquisa no que diz respeito fundamentalmente ao questionamento: 0 que a visibilidade da vida ordinária de mulheres de posições sociais destituídas, na mídia, está produzindo em termos 
de identidade feminina na mesma classe social? Essa indagação, por sua vez, está conectada com a ideia de que vivemos num mundo saturado pela mídia em todos os níveis do processo social e, em função disso, esses processos de comunicação produzem transformações na sociedade, acarretando consequências para outras práticas e espaços sociais, no caso específico, para a produção de identidades femininas.

Os estudos sobre as audiências ocupam um lugar privilegiado no desenvolvimento e no amadurecimento teórico dos estudos de mídia. Em especial, referimo-nos àqueles que se vincularam aos desdobramentos dos estudos culturais e passaram a ser reconhecidos como estudos de recepção. ${ }^{5}$ De modo geral, seu propósito consiste em flagrar um momento específico de interação com a mídia. Numa primeira etapa da sua trajetória, o foco esteve claramente concentrado em identificar possíveis leituras associadas a uma determinada "mensagem", tendo, portanto, um texto (por exemplo, a seleção de um programa de televisão ou, um pouco mais tarde, um gênero (por exemplo, a telenovela) como motivador da pesquisa. ${ }^{6}$

Tendo em vista que o desenvolvimento dos estudos de recepção têm se apresentado tanto através de continuidades quanto de rupturas, destaca-se o deslocamento de um engajamento direto com textos específicos para um enfoque concentrado na compreensão de determinações contextuais, ou seja, para a investigação de múltiplas articulações da mídia na vida cotidiana, transformando-se em estudos de consumo midiático. Se, de um lado, essa alteração de foco pode ser vista em ruptura com a primeira abordagem, por outro, é possível também entendê-la como continuidade, já que permanece circunscrita ao que ocorre nos limites desse espaço.

Ao descrever o desenvolvimento anglo-americano dos estudos das audiências, Gomes (2004, p. 191) avalia que "os estudos mais caracteristicamente situados nessa tendência [de consumo midiático] tentam relacionar o consumo cultural com a experiência social dos membros do público". A mesma autora reconhece a existência de uma segunda tendência dentro dos estudos de consumo midiático, identificada em pesquisas que se preocupam com 0 prazer obtido no consumo de determinados produtos midiáticos. No entanto, do nosso ponto de vista, nenhuma delas chega a compor uma abordagem em completa ruptura com os estudos de recepção. Isto é, mesmo que os estudos de consumo midiático se mostrem como uma reconfiguração dos estudos de recepção, afastando-se de uma análise mais centrada na relação mensagem/receptor, permanecem preocupados com o papel que os meios ocupam num determinado momento no cotidiano de consumidores. Ronsini (2010, p. 2) parece compartilhar de nossa avaliação ao observar que, apesar da bifurcação entre a perspectiva do consumo de Néstor 
García Canclini e a dos usos sociais, associada à Martín-Barbero, "os termos recepção e consumo são utilizados frequentemente como sinônimos para indicar o conjunto dos processos sociais de apropriação dos produtos da mídia". No entanto, a autora faz um esforço para identificar possíveis diferenciações entre as duas perspectivas latinoamericanas, destacando que, na primeira,

\begin{abstract}
a) existe aí uma pluralidade de textos e não um texto específico para ser decifrado; b) não há preocupação em considerar teoricamente as mediações que constituem o processo de dar sentido à mídia e tampouco os detalhes empíricos que envolvem o conhecimento do papel delas; c) 0 consumo é a interpretação que 0 investigador faz das práticas do investigado, isto é, do uso dos bens na rotina de quem usufrui deles e, em menor medida, se caracteriza pela dupla hermenêutica da recepção (RONSINI, 2010, p. 3).
\end{abstract}

Do nosso ponto de vista, mesmo esse esforço para revelar certo afastamento entre essas abordagens, acaba salientando uma convergência final: a preocupação com a presença localizada da mídia numa determinada ocasião, o que implica, obviamente, numa direcionalidade específica - da mídia para os sujeitos. Sendo assim, concluímos que os estudos de recepção, no âmbito do projeto em discussão, podem apenas contribuir para a identificação das transformações que ocorrem entre emissores e receptores mediante a influência de determinados textos da mídia, pressupondo que tal lógica transformativa age numa determinada direção que tem na mídia seu ponto de partida. 0 mesmo vale para os estudos de consumo midiático, embora esses constituam, em certa medida, um foco mais alargado, como já mencionado. Na avaliação de Dover (2007),

$$
\begin{aligned}
& \text { os estudos de audiência têm olhado com } \\
& \text { sucesso para quem consome o quê e, de certa } \\
& \text { forma, porque e com quem, mas têm prestado } \\
& \text { relativamente pouca atenção empírica aos pro- } \\
& \text { cessos sociais que estão além do momento do } \\
& \text { encontro textual - mesmo quando o contexto } \\
& \text { cotidiano é considerado. }
\end{aligned}
$$

Portanto, a atenção e a investigação focada nos encontros dos receptores/consumidores e respectivos textos e/ou mídia, embora relevante e pertinente, não responde a questionamentos sobre as consequências da mídia para a prática social como um todo, sendo essa a direção de nossa segunda questão de pesquisa. Por essa razão, as análises discretas da recepção, e mesmo do consumo, embora valiosas, não são apropriadas para dar suporte à análise que se pretende.

Resta apreciar, sinteticamente, a exemplo do que foi feito com os estudos de recepção e de consumo midiático, os estudos de identidade cultural (nacional, regional, juvenil, de gênero, étnica, entre outras), entendendo-a como sendo "0 conjunto daquelas características pelas quais os grupos sociais se definem como grupos: [ou seja,] aquilo que eles são. Aquilo que eles são, entretanto, é inseparável daquilo que eles não são, daquelas características que os fazem diferentes de outros grupos", considerando-se as "condições sociais" (SILVA apud MEYER, 2000, p. 103).

Nesses processos de diferenciação/identificação, 
isto é, de produção de identidades, as

representações postas em circulação por distintas mídias e/ou práticas simbólicas são fundamentais. Segundo Dover (2007), uma atenção concentrada exatamente em tais representações midiáticas ou, como a autora prefere denominá-las, "representações textuais", é o que define atualmente os estudos de identidades, vinculados aos estudos de mídia. ${ }^{7}$

Em certa medida, essa opção é justificada tendo em vista que, no contexto dos estudos culturais, o aporte de Stuart Hall, o qual concebe as identidades como política e culturalmente construídas, em momentos históricos particulares, adquire uma repercussão incontestável.

Apesar da referência ao fato de que elas são historicamente condicionadas e de que eventos, pessoas, relações e estruturas tenham existência material, o autor destaca que a "identidade é sempre em parte uma narrativa, sempre em parte um tipo de representação. Está sempre dentro da representação" (HALL, 1991, p. 49). Daí a importância que a forma discursiva adquire nesses estudos.

Como já assinalamos, uma parte da nossa investigação, também, está concentrada na análise de um conjunto de representações que produz uma ideia de mulheres destituídas na tentativa de posicioná-las e produzir uma identidade particular. Contudo, queremos explorar, em combinação com a estratégia recém mencionada, a possibilidade de investigar as identidades de mulheres destituídas, concentrando nossa atenção nas formas pelas quais essas identidades são construídas localizadamente mediante práticas. 0 estudo de tais práticas implica em atentar para a ação humana numa organização social. Tratase de observar que "os atores se engajam em projetos concretos, informados pela cultura, mas também produzindo e reproduzindo-a na prática". Nessa abordagem, os atores agem, mesmo que improvisadamente, mediante certos padrões, sendo que "os padrões refletem não somente a cultura, mas o contexto da ação em campos de poder e de interesses concorrentes" (CALHOUN; SENNET, 2007, p. 10). 0 foco nas práticas, em especial daquelas orientadas pela mídia, pretende descentrar a análise tanto das representações, quanto das relações discretas entre os atores e a mídia, implicadas tanto nos estudos de recepção quanto nos de consumo midiático. Assim, nossa pesquisa compromete-se com o desafio de construir pontes entre a organização social, a ação social e a produção de sentido, sem deixar de atentar para a especificidade da mídia na modelagem de comportamentos e identidades.

\section{Referências}

BOURDIEU, Pierre. A dominação masculina. Rio de Janeiro: Bertrand Brasil, 2007. 
CALHOUN, Craig; SENNET, Richard.

Introduction. In: CALHOUN, Craig; SENNET,

Richard (Org.). Practicing culture. Londres;

Nova York: Routledge, 2007.

DOVER, Caroline. Everyday Talk: Investigating Media

Consumption and Identity Amongst School Children.

Particip@tions, v. 4, n. 1, 2007.

ESCOSTEGUY, Ana Carolina Damboriarena. The

Media Visibility of Disadvantaged Social Classes

within Brazilian Mediascape. 2011. Disponível em:

< http://www.westminster.ac.uk/research/a-z/camri/

seminars/camri-seminar-calendar/2011-seminars/

the-visibility-of-disadvantaged-social-classes-within-

the-brazilian-mediascape > . Acesso em: 07 abr. 2011.

ESCOSTEGUY, Ana Carolina; JACKS, Nilda.

Comunicação e Recepção. São Paulo:

Hacker, 2005.

FRANCHETTO, Bruna; CAVALCANTI, Maria Laura;

HEILBORN, Maria Luiza. Antropologia e feminismo.

In: FRANCHETTO, Bruna et al. (Org.). Perspectivas

antropológicas da mulher. Rio de Janeiro: Zahar

Editores, 1981.

GOMES, Itania Maria Mota. Efeito e recepção. Rio

de Janeiro: E-papers, 2004.

HALL, Stuart. Notas sobre a desconstrução

do 'popular'. In: HALL, S. Da diáspora.

Identidades e mediações culturais. Belo

Horizonte: Editora UFMG, 2003.

. Old and new identities, old and new

ethnicities. In: KING, Anthony D. (Org.) Culture,
Globalization and World-System. Londres:

Macmillan, 1991.

MATA, Maria Cristina. Género, lenguaje, comunicación. Signo y pensamiento. Bogotá. n. $28,1996$.

MATTOS, Patrícia. A mulher moderna numa sociedade desigual. In: SOUZA, Jessé (Org.). A invisibilidade da desigualdade brasileira. Belo Horizonte: Editora UFMG, 2006.

MEYER, Dagmar E. Estermann. Identidades traduzidas. Cultura e docência teuto-brasileiroevangélica no Rio Grande do Sul. Santa Cruz do Sul: EDUNISC, 2000.

RONSINI, Veneza. A perspectiva das mediações de Jesús Martín-Barbero (ou como sujar as mãos na cozinha da pesquisa empírica de recepção. In: ENCONTRO DA COMPÓS, 19., 2010. Rio de Janeiro. Anais... Rio de Janeiro: COMPÓS, 2010.

SANTOS, José Alcides Figueiredo. Posições de classe destituídas no Brasil. In: SOUZA, Jessé (Org.). A ralé brasileira: quem é e como vive. Belo Horizonte: UFMG, 2009.

SCOTT, Joan. Gender: a useful category of historical analysis. The American Historical Review, v. 91, n. 5, 1986.

SOUZA, Jessé (Org.). Ralé Brasileira: quem é e como vive. Belo Horizonte: Editora UFMG, 2009. . (Org.). A invisibilidade da desigualdade brasileira. Belo Horizonte: Editora UFMG, 2006. 
STOLKE, Verena. La mujer es puro cuento: la cultura

del gênero. Estudos Feministas, Florianópolis, v. 12, n. 2, p. 77-105, 2004.

WOODWARD, Kathryn. Identidade e diferença: uma

introdução teórica e conceitual. In: SILVA, Tomaz

Tadeu da (Org.). Identidade e diferença. Petrópolis,

RJ: Vozes, 2000. 
The study of social class and gender within the context of media-oriented practices: theoretical approaches

\section{Las relaciones de clase y género en el contexto de prácticas orientadas por los medios de comunicación: apuntes teóricos}

\section{Resumen:}

El objetivo aquí es presentar una discusión teórica sobre dos pilares centrales del proyecto $L a$ visibilidad de la vida cotidiana de las mujeres destituidas en los medios de comunicación (CNPq/ 2010): a) la intersección de las categorías de posición de clase y género, y b) el carácter único de los estudios sobre identidad en relación con los estudios de recepción de los medios de comunicación y el consumo. La razón por la que estos temas se ponen de relieve dicen respecto a la diversidad de interpretaciones en circulación acerca de ellos y, por lo tanto, asume la aclaración de las posiciones. Respecto al primer objetivo, se pretende que la relación entre clase y género colabore en la percepción de la importancia relativa de cada uno de estos términos. En el segundo, partimos de la suposición de que hay tres líneas diferentes - los estudios de recepción, de consumo y de identidad - que tienen objetos distintos, por lo tanto, mantienen una distinción entre ellos, a pesar de las estrategias metodológicas puedan ser convergentes.

\section{Palabras clave:}

Relaciones de clase. Relaciones de género. Mujeres destituidas. Prácticas orientadas por la media. 


\section{Expediente}

A revista E-Compós é a publicação científica em formato eletrônico da Associação Nacional dos Programas de Pós-Graduação em Comunicação (Compós). Lançada em 2004, tem como principal finalidade difundir a produção acadêmica de pesquisadores da área de Comunicação, inseridos em instituições do Brasil e do exterior.
E-COMPÓS I www.e-compos.org.br I E-ISSN 1808-2599

Revista da Associação Nacional dos Programas de Pós-Graduação em Comunicação.

Brasília, v.14, n.2, maio/ago. 2011

A identificação das edições, a partir de 2008 passa a ser volume anual com três números.

\section{CONSELHO EDITORIAL}

Afonso Albuquerque, Universidade Federal Fluminense, Brasil Alberto Carlos Augusto Klein, Universidade Estadual de Londrina, Brasil Alex Fernando Teixeira Primo, Universidade Federal do Rio Grande do Sul, Brasil Ana Carolina Damboriarena Escosteguy, Pontifícia Universidade Católica do Rio Grande do Sul, Brasil

Ana Gruszynski, Universidade Federal do Rio Grande do Sul, Brasil Ana Silvia Lopes Davi Médola, Universidade Estadual Paulista, Brasi André Luiz Martins Lemos, Universidade Federal da Bahia, Brasil Ângela Freire Prysthon, Universidade Federal de Pernambuco, Brasil Angela Cristina Salgueiro Marques, Faculdade Cásper Líbero (São Paulo), Brasil Antônio Fausto Neto, Universidade do Vale do Rio dos Sinos, Brasil Antonio Carlos Hohlfeldt, Pontifícia Universidade Católica do Rio Grande do Sul, Brasil Antonio Roberto Chiachiri Filho, Faculdade Cásper Libero, Brasil Arlindo Ribeiro Machado, Universidade de São Paulo, Brasil Arthur Autran Franco de Sá Neto, Universidade Federal de São Carlos, Brasil Benjamim Picado, Universidade Federal Fluminense, Brasil César Geraldo Guimarães, Universidade Federal de Minas Gerais, Brasil Cristiane Freitas Guttreind, Pontifícia Universidade Católica do Rio Grande do Sul, Brasi Denilson Lopes, Universidade Federal do Rio de Janeiro, Brasil Denize Correa Araujo, Universidade Tuiuti do Paraná, Brasil Edilson Cazeloto, Universidade Paulista , Brasil Eduardo Peñuela Cañizal, Universidade Paulista, Brasi Eduardo Vicente, Universidade de São Paulo, Brasi Eneus Trindade, Universidade de São Paulo, Brasil Erick Felinto de Oliveira, Universidade do Estado do Rio de Janeiro, Brasil Florence Dravet, Universidade Católica de Brasília, Brasil Francisco Eduardo Menezes Martins, Universidade Tuiuti do Paraná, Brasi Gelson Santana, Universidade Anhembi/Morumbi, Brasil Gilson Vieira Monteiro, Universidade Federal do Amazonas, Brasi Gislene da Silva, Universidade Federal de Santa Catarina, Brasil Guillermo Orozco Gómez, Universidad de Guadalajara Gustavo Daudt Fischer, Universidade do Vale do Rio dos Sinos, Brasil Hector Ospina, Universidad de Manizales, Colômbia Herom Vargas, Universidade Municipal de São Caetano do Sul, Brasil leda Tucherman, Universidade Federal do Rio de Janeiro, Brasil Inês Vitorino, Universidade Federal do Ceará, Brasi Janice Caiafa, Universidade Federal do Rio de Janeiro, Brasil Jay David Bolter, Georgia Institute of Technology Jeder Silveira Janotti Junior, Universidade Federal de Pernambuco, Brasil João Freire Filho, Universidade Federal do Rio de Janeiro, Brasi
John DH Downing, University of Texas at Austin, Estados Unidos José Afonso da Silva Junior, Universidade Federal de Pernambuco, Brasil José Carlos Rodrigues, Pontifícia Universidade Católica do Rio de Janeiro, Brasil José Luiz Aidar Prado, Pontifícia Universidade Católica de São Paulo, Brasil José Luiz Warren Jardim Gomes Braga, Universidade do Vale do Rio dos Sinos, Brasil Juremir Machado da Silva, Pontifícia Universidade Católica do Rio Grande do Sul, Brasil Laan Mendes Barros, Universidade Metodista de São Paulo, Brasil Lance Strate, Fordham University, USA, Estados Unidos Lorraine Leu, University of Bristol, Grã-Bretanha Lucia Leão, Pontifícia Universidade Católica de São Paulo, Brasil Luciana Panke, Universidade Federal do Paraná, Brasil Luiz Claudio Martino, Universidade de Brasilia, Brasil Malena Segura Contrera, Universidade Paulista, Brasil Márcio de Vasconcellos Serelle, Pontifícia Universidade Católica de Minas Gerais, Brasil Maria Aparecida Baccega, Universidade de São Paulo e Escola Superior de Propaganda e Marketing, Brasil

Maria das Graças Pinto Coelho, Universidade Federal do Rio Grande do Norte, Brasil Maria Immacolata Vassallo de Lopes, Universidade de São Paulo, Brasil Maria Luiza Martins de Mendonça, Universidade Federal de Goiás, Brasil Mauro de Souza Ventura, Universidade Estadual Paulista, Brasil Mauro Pereira Porto, Tulane University, Estados Unidos Nilda Aparecida Jacks, Universidade Federal do Rio Grande do Sul, Brasi Paulo Roberto Gibaldi Vaz, Universidade Federal do Rio de Janeiro, Brasi Potiguara Mendes Silveira Jr, Universidade Federal de Juiz de Fora, Brasil Renato Cordeiro Gomes, Pontifícia Universidade Católica do Rio de Janeiro, Brasil Robert K Logan, University of Toronto, Canadá

Ronaldo George Helal, Universidade do Estado do Rio de Janeiro, Brasil Rosana de Lima Soares, Universidade de São Paulo, Brasil Rose Melo Rocha, Escola Superior de Propaganda e Marketing, Brasil Rossana Reguillo, Instituto de Estudos Superiores do Ocidente, Mexico Rousiley Celi Moreira Maia, Universidade Federal de Minas Gerais, Brasil Sebastião Carlos de Morais Squirra, Universidade Metodista de São Paulo, Brasi Sebastião Guilherme Albano da Costa, Universidade Federal do Rio Grande do Norte, Brasil

Simone Maria Andrade Pereira de Sá, Universidade Federal Fluminense, Brasil Tiago Quiroga Fausto Neto, Universidade de Brasília, Brasi Suzete Venturelli, Universidade de Brasília, Brasil Valério Cruz Brittos, Universidade do Vale do Rio dos Sinos, Brasil Valerio Fuenzalida Fernández, Puc-Chile, Chile Veneza Mayora Ronsini, Universidade Federal de Santa Maria, Brasil Vera Regina Veiga França, Universidade Federal de Minas Gerais, Brasil

\section{COMISSÃO EDITORIAL}

Adriana Braga I Pontifícia Universidade Católica do Rio de Janeiro, Brasil Felipe Costa Trotta I Universidade Federal de Pernambuco, Brasil

CONSULTORES AD HOC

Bárbara Heller, Universidade Paulista, Brasil

Luciana Mielniczuk, Universidade Federal do Rio Grande do Sul, Brasil Micael Herschmann, Universidade Federal do Rio de Janeiro, Brasil EDIČ̃̃ DE TEXTO E RESUMOS I Susane Barros SECRETÁRIA EXECUTIVA I Juliana Depiné EDITORAÇ̃o ELETRÔNICA I Roka Estúdio TRADUÇÃO I Sabrina Gledhill, Sieni Campos, Robert Finnegan
COMPós I www.compos.org.br

Associação Nacional dos Programas de Pós-Graduação em Comunicação

Presidente

Julio Pinto

Pontifícia Universidade Católica de Minas Gerais, Brasi

juliopinto@pucminas.br

Vice-presidente

Itania Maria Mota Gomes

Universidade Federal da Bahia, Brasi

itania@ufba.br

Secretária-Gera

Inês Vitorino

Universidade Federal do Ceará, Brasil

inesvict@gmail.com 